\title{
HUBUNGAN ANTARA ROLE STRESSOR DAN KOMITMEN ORGANISASIONAL DENGAN TURNOVER INTENTION
}

\author{
Ivan Aries Setiawan \\ Program Studi Manajemen \\ STIE STAN Indonesia Mandiri, Jl. Jakarta No. 79 Bandung
}

\begin{abstract}
ABSTRAK
Penelitian ini bertujuan untuk mengkaji hubungan antara role stressor yang terdiri atas role ambiguity dan role conflict, serta komitmen organisasional dengan turnover, mengingat keterkaitan antara vaiabel-variabel tersebut masih menunjukkan inkonsistensi hasil-hasil penelitian. Beberapa penelitian menunjukkan bahwa kedua jenis role stressor tersebut merupakan prediktor yang signifikan bagi turnover, namun berbagai penelitian lainnya menunjukkan bahwa role stressor dan komitmen organisasional bukan merupakan prediktor yang signifikan. Penelitian ini menggunakan 61 responden dari satu perusahaan yang berlokasi di dua kota. Mengingat penelitian ini bersifat cross-section, maka turnover intention digunakan sebagai proksi dari turnover. Teknik analisis yang digunakan adalah analisis jalur. Hasil penelitian menunjukkan role ambiguity dan role conflict merupakan prediktor yang signifikan bagi komitmen organisasional. Namun dari kedua jenis role stressor tersebut, hanya role conflict yang memiliki hubungan negatif dengan turnover intention. Terakhir, temuan menunjukkan bahwa komitmen organisasional merupakan prediktor penting bagi turnover intention. Bagian akhir paper ini menyajikan beberapa keterbatasan.
\end{abstract}

Kata kunci : turnover, turnover intention, role stressors, role conflict, role ambiguity, komitmen organisasional, analisis jalur.

\section{PENDAHULUAN}

Menurut Setiawan dan Ghozali (2006:13), landasan teori-teori mengenai turnover dapat dirunut kepada pemikiran yang dikemukakan March dan Simon (1958) yang menyatakan bahwa turnover pegawai merupakan hasil dari persepsi individual mengenai desirability yang mendorong munculnya teori-teori beraliran psikologi (psychological school atau push theory) dan ease of movement yang mendorong munculnya teori-teori berbasis ilmu ekonomi (labor market school atau pull theory). Psychological school terutama berhubungan dengan afeksi dan menekankan pada dimensi keputusan terhadap turnover, sementara labor market school menekankan pada pengaruh-pengaruh variabel eksternal seperti peluang pekerjaan.

Push theory berorientasi psikologis (psychologically-oriented) yang memfokuskan pada hubungan antara persepsi dan sikap terhadap pekerjaan. Beberapa studi yang berbasis psychological school diantaranya menggunakan variabel-variabel 
seperti kepuasan kerja, komitmen organisasional dan keterlibatan kerja (Setiawan dan Ghozali 2006:14).

Turnover dapat fungsional atau disfungsional. Turnover adalah fungsional jika yang meninggalkan organisasi merupakan pegawai yang dianggap layak untuk keluar, dengan demikian, memberikan kesempatan bagi masuknya orang yang bermotivasi atau berkemampuan lebih tinggi, membuka kesempatan promosi, serta memberikan ide-ide baru dan segar bagi organisasi (Campion, 1991).

Tingginya popularitas turnover karena dianggap disfungsional. Turnover dapat disfungsional jika yang keluar adalah pegawai yang tidak diharapkan keluar, karena turnover dapat mengganggu organisasi dan mengurangi efektivitas organisasi dan mengganggu vitalitas organisasi (Tang et al., 2000; Cattani et al., 2002). Dari perspektif praktis, pemahaman terhadap faktor mendasar penyebab turnover dapat memberikan pandangan mengenai bagaimana mengendalikan turnover. Secara praktis, meminimumkan turnover tenaga kerja yang memiliki keterampilan (skilled labor) adalah diperlukan karena hal tersebut mengurangi biaya penggantian (replacement costs) dan memelihara pengetahuan serta pengalaman di tempat kerja. Karenanya, studi yang dapat memberikan pemahaman yang lebih mendalam untuk mengurangi turnover sangat relevan.

Berdasarkan push theory, para peneliti berupaya mengidentifikasi konstrukkonstruk yang dapat menjelaskan turnover. Beberapa peneliti mengemukakan bahwa konstruk yang dapat menjelaskan turnover adalah komitmen organisasional (Meyer et al., 1991; Kline et al., 1991). Mereka menemukan adanya hubungan yang signifikan di antara dua konstruk tersebut.

Namun demikian, dalam berbagai studi yang dilakukan masih terdapat isu yang memerlukan kajian lebih lanjut. Beberapa peneliti kuantitatif menemukan bahwa hubungan antara komitmen organisasional dan turnover hanya menghasilkan korelasi yang kecil meskipun signifikan (Cohen (1993; Mathieu dan Zajac, 1990; Kirschenbaum dan Mano-Negrin (1999). Bahkan, MacKenzie et al. (1998) justru tidak menemukan hubungan yang signifikan antara komitmen organisasional dan turnover.

Beberapa peneliti mengembangkan model turnover dengan menambahkan beberapa variabel sikap (attitudes) baik sebagai anteseden konstruk komitmen organisasional maupun konstruk turnover. Para peneliti diantaranya menambahkan role 
stressor yang terdiri atas role conflict dan role ambiguity sebagai prediktor. Hasil berbagai studi cukup bervariasi. Hasil studi Good et al. (1996) menunjukkan bahwa role ambiguity tidak memiliki efek yang signifikan bagi komitmen organisasional. Sebaliknya, Ameen et al. (1995) serta Cahyono dan Ghozali (2002) menemukan bahwa role conflict tidak memiliki efek yang signifikan terhadap komitmen organisasional. Han et al. (2015) menemukan bahwa role conflict maupun role ambiguity tidak memiliki efek yang signifikan bagi turnover intention.

Karenanya, isu-isu yang belum terselesaikan tersebut merupakan topik yang penting dan menarik untuk diteliti. Pada penelitian ini, konstruk turnover akan diproksi oleh turnover intention (turnover intention).

\section{REVIEW LITERATUR}

Cascio (1990) mendefinisikan turnover sebagai penarikan diri dari organisasi secara permanen secara sukarela (voluntarily) seperti pensiun, atau tidak sukarela (involuntarily) seperti pemecatan. Diantara kedua jenis turnover, voluntary turnover merupakan pusat perhatian para peneliti (Lee dan Mitchell, 1994). Dalam berbagai studi, para peneliti memproksi atau bahkan mengganti konstruk turnover dengan konstruk turnover intention (turnover intention). Tett dan Meyer (1993) menyatakan bahwa turnover intention bermakna suatu kesadaran dan kesengajaan untuk meninggalkan organisasi. Dalton et al. (1999) menyatakan bahwa penggunaan turnover intention sebagai proksi turnover aktual sangat dimungkinkan mengingat kondisikondisi:

a. Karena masalah kepraktisan, tidak tersedia data aktual.

b. Turnover aktual mensyaratkan rancangan longitudinal.

Role ambiguity terjadi jika seorang pegawai merasa tidak pasti mengenai tugas dan tanggung jawab yang dibebankan kepadanya Role conflict dapat muncul jika seorang pegawai menerima dua atau lebih harapan atau permintaan yang berbeda dan tidak dapat diselesaikan secara simultan. Role ambiguity dan role conflict merupakan role stressor yang dipandang sebagai anteseden bagi job-related outcome (Mathieu dan Farr, 1991).

Di antara sekian banyak studi tentang role stressor, studi mengenai hubungan langsung antara role conflict, role ambiguity, dan turnover intention tergolong relatif 
jarang dan itupun masih menyisakan kontroversi antar temuan-temuan. Sebagian besar peneliti menghubungkan kedua jenis role stressors tersebut dengan turnover intention secara tidak langsung, namun melalui konstruk lain seperti job insecurity.

Dari hasil penelitiannya, Bedeian dan Armenakis (dalam Netemeyer et al., 1990) menggunakan model kausal dan menemukan efek prediktif yang signifikan dari role conflict dan role ambiguity terhadap kecenderungan seseorang untuk keluar dari organisasi. Namun, studi Netemeyer et al. malah menemukan hasil yang bertentangan dimana kedua jenis role stressors tersebut justru tidak emiliki efek yang signifikan bagi kecenderungan untuk keluar dari organisasi.

Peterson (1995) dalam Helriegel et al. (2001) dari hasil studinya di berbagai negara menyimpulkan bahwa tingginya role conflict dan role ambiguity mendorong perilaku penarikan diri pegawai. Sementara itu peneliti Indonesia, Rahayu (2002) dan Ratnawati (2002) hanya mengkaji efek role conflict terhadap turnover intention dan hasil studinya menyimpulkan bahwa role conflict memiliki efek positif terhadap turnover intention. Ali dan Baloch (2009) berdasarkan hasil studinya menyimpulkan bahwa conflict dan role ambiguity memiliki hubungan positif dengan turnover intention.

Porter et al. (1974) mendefinisikan komitmen organisasional sebagai kekuatan relatif identifikasi individual terhadap suatu organisasi dan keterlibatannya dalam suatu organisasi tertentu, yang dicirikan oleh tiga faktor psikologis:

a. Keinginan yang kuat untuk tetap menjadi anggota organisasi tertentu.

b. Keinginan untuk berusaha sekuat tenaga demi organisasi.

c. Kepercayaan yang pasti dan penerimaan terhadap nilai-nilai dan tujuan-tujuan organisasi (Mayer dan Schoorman, 1992).

Organisasi menilai komitmen pegawai karena mengasumsikan dapat mengurangi perilaku penarikan diri seperti peningkatan kinerja, ketidakhadiran, turnover (Tett dan Meyer, 1993; Mathieu dan Zajac, 1990).

Dalam studinya terhadap kadet angkatan udara Amerika, Lee et al. (1992) menghipotesiskan bahwa komitmen organisasional berhubungan negatif dengan turnover sukarela. Temuan menunjukkan bahwa komitmen organisasional berhubungan negatif signifikan dengan turnover sukarela.

Hasil studi Lee dan Mowday (1987) menunjukkan bahwa komitmen organisasional memiliki hubungan negatif dan merupakan prediktor penting bagi 
turnover intention. Temuan tersebut dikonfirmasikan kembali oleh temuan-temuan lainnya dalam berbagai seting seperti perilaku organisasi, manajemen internasional, pemasaran, dan akuntansi, dimana secara konsisten para peneliti menemukan hubungan negatif signifikan antara kedua konstruk tersebut (Ali dan Baloch, 2009; Gregersen dan Black, 1992; Good et al., 1996; Brown dan Peterson, 1993; Chalim, 2018).

Bukti-bukti empiris yang menghubungkan antara role stressor tersebut dan komitmen organisasi masih relatif jarang (Ratnawati, 2002). Mengutip temuan Jakcson dan Schuller (1985), Netemeyer et al. (1996) menyatakan bahwa konstruk role Ambiguity dan role conflict merupakan kontruk-konstruk yang memiliki hubungan dengan sikap dan perilaku sepeti rendahnya kepuasan kerja dan komitmen organisasional. Demikian pula studi Fogarty (1996) dari studinya menyimpulkan adanya efek negatif role conflict dan role ambiguity terhadap komitmen organisasional.

Dari hasil studi meta analisisnya, Mathieu dan Zajac (1990) serta Cohen (1992) menemukan bahwa role ambiguity dan role conflict, meskipun korelasinya moderat, merupakan anteseden yang signifikan bagi komitmen organisasional. Mathieu dan Farr (1991) menemukan bahwa role strains yang mencakup role conflict dan role ambiguity memiliki efek yang signifikan tergadap komitmen organisasional.

Dalam studinya terhadap manajer department store, Good et al. (1996) menghipotesiskan bahwa role ambiguity dan role conflict memiliki efek negatif terhadap komitmen organisasional. Dari hasil studinya, Good et al. (1996) menyimpulkan bahwa role conflict memiliki efek negatif dan signifikan terhadap komitmen organisasional. Temuan tersebut dikonfirmasikan kembali oleh Priya et al. (2018)

Secara keseluruhan, berdasarkan uraian-uraian tersebut di atas dapat dikembangkan suatu model analisis berikut.

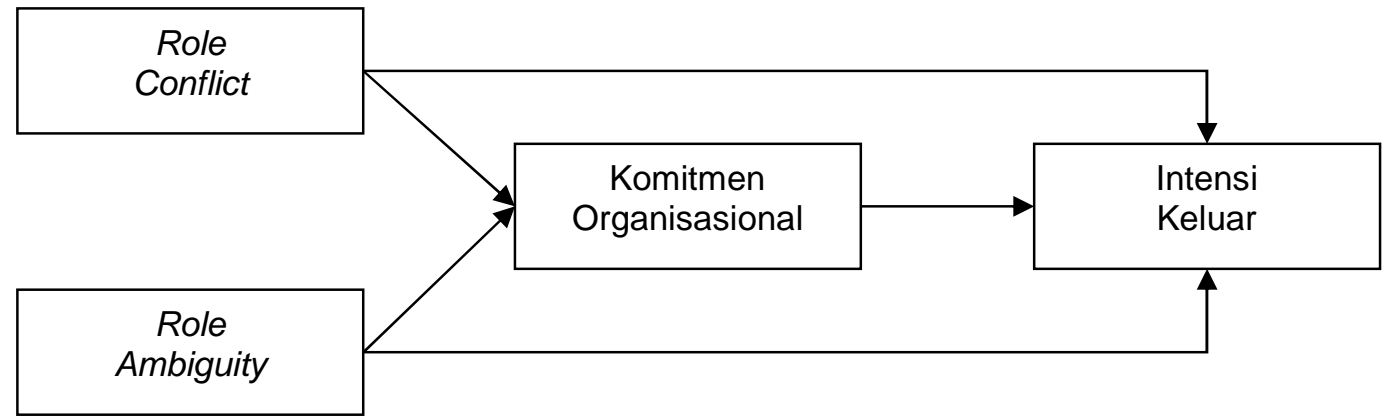

Gambar 1. Model Analisis 
Berdasakan model tersebut di atas, hipotesis yang diajukan pada studi ini:

$\mathrm{H}_{1}$ : Terdapat hubungan positif antara role ambiguity dengan turnover intention

$\mathrm{H}_{2}$ : Terdapat hubungan positif antara role conflict dengan turnover intention

$\mathrm{H}_{3}$ : Terdapat hubungan negatif antara role ambiguity dengan komitmen organisasional

$\mathrm{H}_{4}$ : Terdapat hubungan negatif antara role conflict dengan komitmen organisasional

$\mathrm{H}_{5}$ : Terdapat hubungan negatif antara komitmen organisasional dengan turnover intention.

\section{METODE PENELITIAN}

Sampel terdiri atas 61 pegawai dari suatu perusahaan yang berlokasi di dua kota yang bergerak pada industri manufaktur. Komposisi sampel (subjek) mencakup berbagai tingkatan dalam organisasi. Responden diminta untuk mengisi daftar isian dan kuesioner (self administration) mengenai variabel-variabel yang diteliti dan beberapa karakteristik demografi. Dari total 70 kuesioner yang disebarkan, 61 kuesioner dapat dianalisis.

Komitmen organisasional diukur dengan skala yang dikembangkan oleh Meyer dan Allen (1984). Ukuran komitmen organisasional didasarkan pada tanggapan subjek terhadap serangkaian item yang menggunakan skala tujuh poin Likert-type, yang dimulai dengan angka 1 (Sangat Tidak Setuju) sampai angka 7 (Sangat Setuju). Instrumen role ambiguity dan role conflict mengacu pada kuesioner yang telah dikembangkan oleh Rizzo et al. (1970). Ukuran role ambiguity dan role conflict didasarkan pada tanggapan subjek terhadap serangkaian item yang menggunakan skala lima poin Likert-type, yang dimulai dengan angka 1 (Sangat Salah) sampai angka 5 (Sangat Benar). Turnover intention diukur dengan menggunakan respon terhadap skala empat item yang dikembangkan oleh Farh et al. (1998). Ukuran turnover intention didasarkan pada tanggapan subjek terhadap serangkaian item yang menggunakan skala tujuh-poin, dimulai dengan angka 1 (Sangat Tidak Setuju) sampai angka 7 (Sangat Setuju). 


\section{TEMUAN-TEMUAN}

Tabel 1 menyajikan reliabilitas masing-masing variabel. Dari pengujian reliabilitas nampak bahwa masing-masing instrumen pengukuran adalah reliabel dengan koefisien konsistensi internal cronbach alpha sebagai berikut: role conflict 0.8195 ; role ambiguity 0.0.8961; komitmen organisasional 0.8408; dan turnover intention 0.6169. Koefisien tersebut sesuai dengan rekomendasi Nunnaly (1978) yaitu persyaratan nilai koefisien cronbach's alpha lebih dari 0,60 (Nunnaly, 1978).

Tabel 1. Koefisien Reliabilitas

\begin{tabular}{lc}
\hline \multicolumn{1}{c}{ Variabel } & Reliabilitas \\
\hline Role ambiguity & 0.8961 \\
Role conflict & 0.8195 \\
Komitmen Org. & 0.8408 \\
Turnover intention & 0.6169 \\
\hline
\end{tabular}

Instrumen pengukuran juga memenuhi kriteria validitas yaitu koefisien korelasinya positif dan signifikan (Ghozali, 2001), kecuali untuk item nomor 3 pada turnover intention. Item tersebut tidak disertakan dalam analisis.

Nilai tengah, deviasi standar, dan korelasi bi-variate seluruh variabel disajikan pada Tabel 1 dan Tabel 2.

Tabel 2. Nilai Tengah dan Deviasi Standar

\begin{tabular}{|l|c|r|c|}
\hline Variabel & N & \multicolumn{1}{|c|}{ Mean } & $\begin{array}{c}\text { Std. } \\
\text { Deviation }\end{array}$ \\
\hline Role ambiguity & 61 & 13.8033 & 6.49056 \\
\hline Role conflict & 61 & 28.4918 & 8.80459 \\
\hline Komitmen Org. & 61 & 5.3087 & 0.80858 \\
\hline Turnover intention & 61 & 2.4877 & 0.88085 \\
\hline
\end{tabular}

Korelasi menunjukkan indikasi awal adanya hubungan antar variabe. Dari Tabel 3 Terlihat bahwa korelasi bi-variate seluruh variabel adalah signifikan, kecuali korelasi antara role ambigutiy dengan turnover intention serta role ambiguity dengan role conflict. 
Tabel 3. Korelasi Bi-Variate

\begin{tabular}{|l|c|c|c|}
\hline Variabel & Role conflict & Role amb. & Kom. Org. \\
\hline Role amb. & 0.194 & - & - \\
\hline Kom. Org. & $-0.371^{* *}$ & $-0.311^{*}$ & - \\
\hline Turnover int. & $0.432^{* *}$ & 0.017 & $-0.548^{* *}$ \\
\hline
\end{tabular}

**. Correlation is significant at the 0.01 level (2-tailed).

*. Correlation is significant at the 0.05 level (2-tailed).

Gambar berikut menunjukkan model dan koefisien jalur dari tiap-tiap hubungan yang dihipotesiskan.

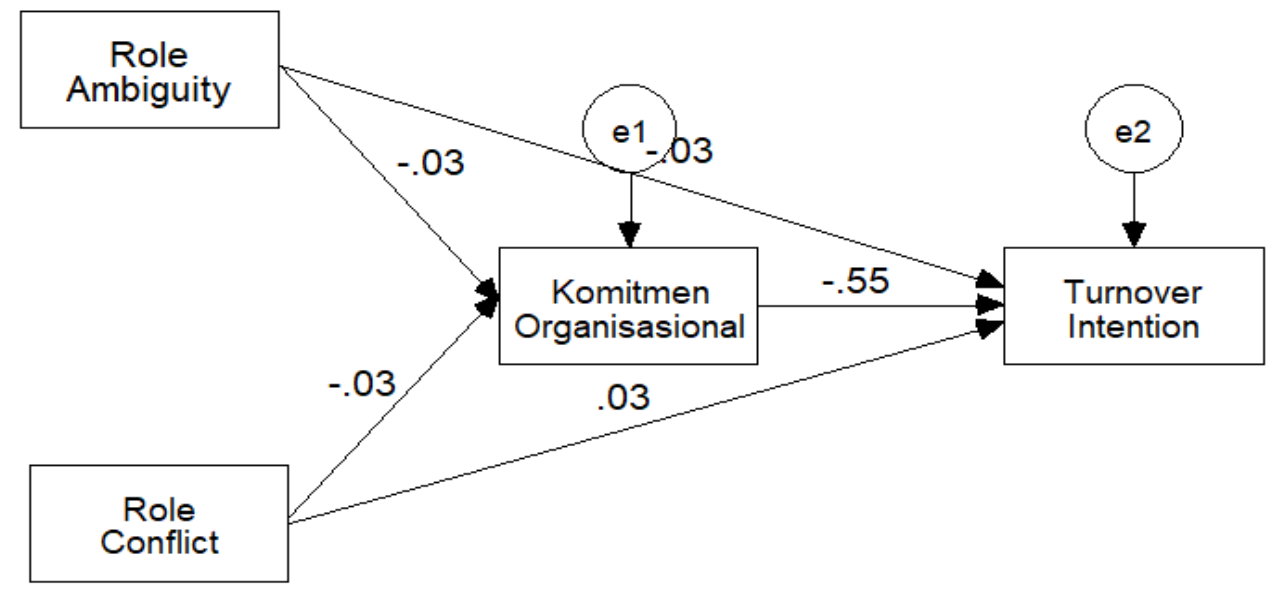

Gambar 2. Model Empiris

Estimasi dan signifikansi masing-masing jalur secara rinci disajikan pada Tabel 4.

Tabel 4. Koefisien Jalur

\begin{tabular}{|c|c|c|c|c|}
\hline Hubungan & Estimasi & S. E. & C. R. & P \\
\hline TI $\leftarrow$ RA & -0.026 & 0.014 & -1.864 & 0.062 \\
\hline TI $\leftarrow$ RC & 0.028 & 0.011 & 2.645 & 0.008 \\
\hline OC $\leftarrow$ RA & -0.031 & 0.014 & -2.142 & 0.032 \\
\hline OC $\leftarrow$ RC & -0.030 & 0.011 & -2.793 & 0.005 \\
\hline TI $\leftarrow$ OC & -0.549 & 0.122 & -4.492 & $* * * *$ \\
\hline
\end{tabular}

Tabel 3. menunjukkan koefisien jalur dari masing-masing hubungan yang dihipotesiskan. 
a. Hipotesis 1 menyatakan terdapat hubungan positif antara role ambiguity dengan turnover intention. Nilai koefisien adalah -0.026 dan signifikan pada level 0,062. Karenanya, hipotesis 1 tidak dapat dikonfirmasikan.

b. Hipotesis 2 menyatakan terdapat hubungan positif antara role conflict dengan turnover intention. Nilai koefisien adalah 0,028 dan signifikan pada level 0,008. Karenanya, hipotesis 2 dapat dikonfirmasikan.

c. Hipotesis 3 menyatakan terdapat hubungan negatif antara role ambiguity dengan komitmen organisasional. Nilai koefisien adalah -0,031 dan signifikan pada level 0,032. Karenanya, hipotesis 3 dapat dikonfirmasikan.

d. Hipotesis 4 menyatakan hubungan negatif antara role conflict dengan komitmen organisasional. Nilai koefisien adalah -0,030 dan signifikan pada 0.010. Karenanya, hipotesis 2 dapat dikonfirmasikan.

e. Hipotesis 5 menyatakan bahwa terdapat hubungan negatif antara komitmen organisasional dengan turnover intention. Nilai koefisien adalah $-0,549$ dan sangat signifikan (highly significant). Karenanya, hipotesis 5 dapat dikonfirmasikan.

Hasil penelitian menunjukan bahwa turnover intention dapat dipengaruhi oleh role conflict. Karenanya dapat dikatakan bahwa semakin tinggi role conflict maka semakin tinggi pula intensi pegawai untuk keluar dari perusahaan. Temuan ini sejalan dengan temuan-temuan Rahayu (2002) dan Ratnawati (2002). Komitmen organisasional memiliki efek negatif terhadap turnover intention. Oleh karenanya, semakin tinggi level komitmen seseorang, maka akan semakin rendah keinginan seseorang untuk keluar dari perusahaan. Temuan ini sejalan dengan temuan-temuan sebelumnya (misalnya Han et al., 2015; Pasewark dan Strawser, 1998).

Temuan juga menunjukkan adanya efek negatif yang signifikan dari role ambiguity dan role conflict terhadap komitmen organisasional. Semakin tinggi role ambiguity dan role conflict, maka diprediksikan semakin rendah komitmen seseorang terhadap perusahaan. Temuan ini mengkonfirmasikan kembali temuan-temuan sebelumnya (misalnya Fogarty 1996; Han et al., 2015)

\section{Keterbatasan}

Beberapa kehati-hatian dan keterbatasan dalam menafsirkan hasil-hasil studi ini perlu dikemukakan. Pertama, efek role ambiguity terhadap komitmen organisasional 
bersifat marginally significant. Karenanya, penggunaan atau penolakan terhadap konstruk role ambiguity secara praktis memerlukan judgment yang matang. Kedua, studi ini dibatasi pada satu perusahaan. Oleh karenanya, hasil studi tidak dapat digeneralisir pada perusahaan atau organisasi lain. Ketiga, studi ini mengkaji turnover intention bukan actual turnover. Meskipun dalam bagian sebelumnya dikemukakan justifikasi pemilihan konstruk dan terdapat korelasi tinggi antara turnover intention dan actual turnover, bagaimanapun juga, turnover intention bukan merupakan jaminan bagi terjadinya actual turnover. Keempat, jumlah sampel yang relatif kecil (61 buah) cukup riskan dalam pengambilan kesimpulan.

\section{DAFTAR PUSTAKA}

Ali, Nazim., and Qadar Bakhsh Baloch. "Predictors of Organizational Commitment and Turnover Intention of Medical Representatives (An Empirical Evidence of Pakistani Companies)." Journal of Managerial Sciences Vol. III No. 2 (2009): 263-273.

Ameen, Elsie C., Cynthia Jackson., William R. Pasewark., and Jerry R. Strawser. "An Empirical Investigation of the Antecedents and Consequences of Job Insecurity on the Turnover intentions of Academic Accountants." Issues in Accounting Education Vol. 10 No. 1 (Spring 1996): 65-82.

Brown, Stephen P., and Robert A. Peterson. "Antecedents and Consequences of Salesperson Job Satisfaction: Meta-Analysis and Assessment of Causal Effects." Journal of Marketing Research Vol. XXX (February 1993): 63-77.

Cahyono, Dwi., dan Imam Ghozali. "Pengaruh Jabatan, Budaya Organisasional dan Konflik Peran terhadap Hubungan Kepuasan Kerja dengan Komitmen Organisasi: Studi Empiris di Kantor Akuntan Publik.” Jurnal Riset Akuntansi Indonesia (2002): 341-354.

Campion, A. Michael. "Meaning and Measurement of Turnover: Comparison of Alternative Measures and Recommendations for Research." Journal of Applied Psychology Vol. 76 No. 2 (1991): 199-212.

Cascio, Wayne F. Costing Human Resources. Boston: PWS-Kent Publishing Company, $3^{\text {rd }}$ ed., 1991.

Cattani, Gino., and Johannes M. Pennings. "Organizational Turnover and the Evolution of Localized Populations." Administrative Science Quarterly (August 2002): 145.Cohen (1993).

Chalim, Asep Saifuddin. "Effect of Job Insecurity, Organizational Commitment, Job Satisfaction on Turnover Intention: A Case Study of New Comer Lecturers at Private Islamic Universities in East Java Province, Indonesia." Jurnal Ilmiah Peuradeun: The International Journal of Social Sciences Vol. 6 No. 2 (2018): 99214. 
Cohen, A. "Organizational Commitment and Turnover: A Meta-Analysis." Academy of Management Journal Vol. 36 No. 5 (1993): 1140-1157.

Dalton, R. Dan., Jonathan L. Johnson., and Catherine M. Daily. "On the use of "Intent to..." Variables in Organizational Research: An Empirical and Cautionary Assessment."

Human Relations Vol. 52 No. 10 (1999): 1337-1350.

Fogarty, Timothy J. "Gender Differences in the Perception of the Work Environment within Large International Accounting Firms." Managerial Auditing Journal, Vol. 11 No. 2 (1996): 10-19.

Good, Linda K., Thomas J. Page., and Clifford E. Young. "Assessing Hierarchical Differences in Job Related Attitude and Turnover Among Retail Managers." Journal of Academy Marketing Research Vol. 24 No. 2 (1996): 148-156.

Gregersen, Hal B., and J. Stewart Black. "Antecedents to Commitment to a Parent Company and a Foreign Operation." Academy of Management Journal Vol. 35 No. 1 (1992): 65-90.

Han, Sang-Sook., Jeong-Won Han., Young-Suk An., and So-Hee Lim. "Effects of Role Stress on Nurses' Turnover Intentions: The Mediating Effects of Organizational Commitment and Burnout." Japan Journal of Nursing Science Vol. 12 (2015): 287-296.

Kirschenbaum, Alan., and Rita Mano-Negrin. "Underlying Labor Market Dimensions of "Opportunities": The Case of Employee Turnover." Human Relations, Vol. 52 No. 10 (1999): 1233-1255.

Kline, Cathy J., and Lawrence H. Peters. "Behavioral Commitment and Tenure of New Employees: A Replication and Extension." Academy of Management Journal Vol. 34 No. 1 (1991): 194-204.

Lee, Thomas W., and Terence R. Mitchell. 1994. "An Alternative Approach: The Unfolding Model of Voluntary Employee Turnover." Academy of Management Review Vol. 19 (1): 51-89.

Mathieu, John E., and Dennis M. Zajac. "A Review and Meta-Analysis of the Antecedents, Correlates, and Consequences of Organizational Commitment." Psychological Bulletin Vol. 108 No. 2 (1990): 171-194.

Meyer, John. P., D. Ramona Bobocel., and Natalie J. Allen. "Development of Organizational Commitment During the First Year of Employment: A Longitudinal Study of Pre- and Post-entry Influences.” Journal of Management Vol. 17 No. 4 (1991): 717-733.

Netemeyer, G. Richard., Mark W. Johnston., and Scot Burton. 1990. "Analysis of Role Conflict and Role Ambiguity in a Structural Equation Framework." Journal of Applied Psychology, Vol. 75 (2): 148-157.

Nunnally. Psychometric Theory. India: McGraw-Hill $2^{\text {nd }}$ ed., 1978. 
Pasewark, William R., and Jerry R. Strawser. "The Determinants and Outcomes Associated with Job Insecurity in a Professional Accounting Environment." Behavioral Research In Accounting Vol. 8 (1996): 91-113.

Priya, K. Hari., K.Kumudha Devi., and S. Hari Hara Sudhan. "Examining the Effect of Role Conflict and Job Stress on Turnover Intention among the Private School Teachers in Vellore District." International Journal of Business and Management Invention Vol. 6 Iss. 1 (2017): 58-63.

Rahayu, Dyah Sih. "Anteseden dan Konsekuensi Tekanan Peran (Role Stress) pada Auditor Independen.” Simposium Nasional Akuntansi IV (2001): 504-522.

Ratnawati, Vince. "Pengaruh Faktor Anteseden, Job Insecurity, dan Konsekuensinya terhadap Keinginan Berpindah Karyawan." Simposium Nasional Akuntansi IV (2001): 411-431.

Setiawan, Ivan Aries., dan Imam Ghozali. 2006. Akuntansi Keperilakuan: Konsep dan Kajian Empiris Perilaku Akuntan. BPFE Univ. Diponegoro. Semarang.

Tang, Thomas Li-Ping., Jwa K. Kim., and David Shin-Hsiung Tang. "Does Attitude toward Money Moderate the Relationship between Intrinsic Job Satisfaction and Voluntary Turnover?" Human Relations Vol. 53 No. 2 (February 2000): 213-245.

Tett, Robert P., and John P. Meyer. "Job Satisfaction, Organizational Commitment, Turnover intention, and Turnover: Path Analyses Based on Meta-Analytic Findings.” Personnel Psychology Vol. 46 (1993): 259-293.

MacKenzie, Scott B., Philip M. Podsakoff., and Michael Ahearne. "Some Possible Antecedents and Consequences of In-Role and Extra-Role Salesperson Performance." Journal of Marketing. 1998, Vol. 62 (July), 87-98.

Wong, Chi-Sum., Chun Hui., and Kenneth S. Law. "Causal Relationship between Attitudinal Antecedent to Turnover." Journal of Applied Psychology Vol. 89 No. 2 (1994): 342-346. 